\title{
Lecturas de derecho administrativo, de Augusto Ramón Chávez Marín
}

Por ÁLVARO ECHEVERRY URUBURU*

Editorial Universidad Santo Tomás, Bogotá, 2005, 214 p.

Como lo indicó el ilustre Magistrado del Consejo de Estado Rafael Ostau de Lafont Pianeta al hacer la presentación del texto editado por la Universidad Santo Tomás, en evento realizado en la anterior feria del libro, no es éste un trabajo que obedezca al formato y estilo tradicional de las obras nacionales del derecho administrativo. Se trata, en efecto, de un trabajo que aborda ciertos temas de sustancial importancia en esta disciplina, ordenados a partir de los grandes capítulos en que se puede dividir hoy día este campo del conocimiento jurídico.

Son, sin duda, documentos que abren la puerta al debate académico, que concluyen sobre ciertas discusiones, que plantean dudas, que ofrecen reflexiones, nacidos del atesoramiento de inquietudes de un académico que ha trasegado por el pensamiento jurídico a lo largo de varios años de actividad docente y de un ejercicio profesional atento a las transformaciones de la norma administrativa. Se ve así bien llamada esta obra, pues está integrada por unos documentos que constituyen lecturas para la reflexión, para el análisis, para la búsqueda del saber, para la consolidación del conocimiento y la formación de criterios, que mucho valor pueden representar tanto para los alumnos de pregrado como para quienes aspiren a la profundización del conocimiento en la dogmática y crítica del ordenamiento positivo administrativo.

El autor de Dos estudios de tópica jurídica (Bogotá, Procuraduría General de la Nación, 2004) toca una serie de materias que representan para el derecho administrativo temas de una gran relevancia, comenzando desde las actuales transformaciones de esta disciplina y los retos que enfrenta en el marco de la globalización, las autoridades administrativas de nuevo cuño y los vientos de la privatización (Lectura № 1: Las transformaciones del Estado y del derecho administrativo en el marco de la integración y la globalización), hasta llegar al examen de aspectos cuyo interés desborda el de los abogados, pues afecta a la sociedad entera, como es el de los servicios públicos domiciliarios (Lectura No 12: La regulación de los servicios públicos en Colombia).

* Decano de la Facultad de Derecho de la Universidad Santo Tomás. 
Examinado el primero de los temas mencionados, propio de la que identifica como Teoría General del Derecho Administrativo (Capítulo II), el autor se introduce en el estudio de la estructura administrativa a través de la exploración de Los conceptos de órgano y persona jurídica pública, examinando allí mismo algunos aspectos de su proyección en el derecho administrativo (Lectura № 2). Pasa luego a elaborar una Aproximación comparativa a las reformas administrativas de 1968 y 1998 (Lectura № 3), así como El concepto de estructura de la administración pública (Lectura № 4).

Asunto de mucha novedad, dados los cambios de tratamiento que sobre el tema se hacen en la Constitución de 1991 y la Ley 489 de 1998, es el de La responsabilidad en la delegación administrativa (Lectura No 5), el cual se concentra precisamente en el alcance de la responsabilidad de los servidores públicos delegatario y delegante, al intervenir en la relación que esa figura jurídica conlleva y en el desarrollo de las tareas que se desenvuelven como producto de la misma. En esta oportunidad el escritor se ocupa analíticamente de la jurisprudencia de la Corte Constitucional sobre la materia, con enfoque pedagógico pero a la vez crítico, como es su característica a lo largo de todos los documentos.

En el campo del ordenamiento territorial se destaca especialmente la lectura relativa a La ley de orgánica de ordenamiento territorial en la Constitución de 1991. Elementos para su comparación con el derecho español (Lectura № 6). En esta ocasión el profesor Chávez Marín observa el tema con el mayor rigor y apoyándose en la jurisprudencia y la doctrina nacional y extranjera hace un detallado examen comparativo de este tipo de ley, una vez ha destacado los aspectos más importantes de la naturaleza jurídica de la misma y sus alcances temáticos. No sobra señalar la importancia de este análisis en los tiempos que corren, cuando el Congreso de Colombia debate de nuevo un proyecto de ley orgánica de ordenamiento territorial y se requiere el conocimiento preciso sobre su alcance constitucional.

En el importante campo de la Actividad convencional de la administración (capítulo V), el profesor de pregrado y posgrado de la Facultad de Derecho de la Universidad Santo Tomás, presenta dos trabajos que lo ubican claramente a la cabeza de los estudiosos sobre este tipo de gestión que muy poco o nada se ha examinado en Colombia. En ellos presenta algunas ideas generales de lo que se asoma a una Teoría general de los convenios de la administración. En el marco de esta propuesta apenas sugerida por el autor, se dedica a estudiar un tipo específico de convenios que representa gran interés para la actividad tanto del Estado central como de las entidades territoriales, duramente cuestionada por la Corte Constitucional y los organismos de control fiscal y disciplinario: Los convenios celebrados con organismos internacionales de cooperación (Lectura № 9). No se escapan tirios y troyanos al ojo crítico de este profesor tomista, que examina a partir de su sistema de pensamiento las diferentes posturas de las autoridades que han intervenido de una u otra forma en la discusión originada en la utilización de esta herramienta contractual: el autor pone al descubierto el uso sesgado de la misma por sujetos contractuales tanto públicos como privados, así como el paso en falso dado por parte de los órganos reguladores y de control constitucional, fiscal y disciplinario, a causa de los equívocos originados en la concepción y en la práctica en torno a dicha figura.

Al reseñar el texto del ya clásico autor francés Jean Rivero, denominado El hurón en el palacio real o reflexiones ingenuas sobre el recurso por exceso de poder (Lectura No 10), que forma parte del recientemente traducido Páginas de derecho administrativo (Traducción dirigida por Libardo Rodríguez Rodríguez, Bogotá: Temis, 2002), el autor se introduce en una visión comparada de las acciones con- 
tenciosas, que sirve de tránsito para hacer una serie de interesantes reflexiones sobre la justicia en el derecho administrativo y particularmente La justicia arbitral y su competencia en lo contencioso administrativo (Lectura № 11). En este trabajo se examinan especialmente ciertos fallos del Consejo de Estado que resultan claves para el entendimiento de la discusión que en cuanto al alcance de la competencia de los tribunales de arbitramento en temas de derecho administrativo se ha generado en los últimos años en el seno de la doctrina y la jurisprudencia nacionales.
Se cierra bien el libro al ofrecer al lector una visión marcadamente social sobre el interesante tema del servicio público domiciliario, que desborda una mera apreciación dogmática de esta materia, pues se plantean numerosas inquietudes sobre los alcances de la regulación existente y se mira cómo deberían ser las normas y cómo debería gestionarse esta actividad fundamental para los intereses de la comunidad, si se atendieran criterios que consultaran cabalmente los postulados constitucionales del Estado social de derecho erigido en la Carta de 1991 (Lectura No 12). 